\title{
PENGARUH STRATEGI PEMBELAJARAN INKUIRI TERBIMBING DAN TERHADAP KEMAMPUAN PEMECAHAN MASALAH FISIKA PADA MATERI SUHU DAN KALOR DILIHAT DARI KEMAMPUAN AWAL SISWA
}

\author{
Muhammad Sayyadi, Arif Hidayat, Muhardjito \\ Prodi Pendidikan Fisika, Pascasarjana, Universitas Negeri Malang \\ Jl.Semarang No. 5 Malang \\ mhmdsayyadi@gmail.com
}

\begin{abstract}
Abstrak
Penelitian ini bertujuan untuk mengetahui pengaruh strategi pembelajaran Inkuiri terbimbing terhadap kemampuan pemecahan masalah fisika pada materi suhu dan kalor dilihat dari kemampuan awal siswa. Penelitian ini merupakan penelitian kuasi eksperimen menggunakan dua kelas yaitu kelas eksperimen dan kelas kontrol. Populasi penelitian ini adalah kelas X SMA Negeri 10 Malang semester genap tahun ajaran 2015/2016. Sampel terdiri atas kelas eksperimen dan kelas kontrol yang dipilih secara cluster random sampling. Kelas eksperimen belajar menggunakan Inkuiri terbimbing dan kelas kontrol belajar menggunakan Pembelajaran Konvensional. Pembelajaran dilakukan pada materi suhu dan kalor. Data yang didapatkan dianalisis menggunakan Analisis varian dua Jalur. Pengaruh pembelajaran diuji dengan uji Tukey. Hasil analisis menunjukkan ada pengaruh kemampuan awal siswa terhadap kemampuan pemecahan masalah serta kemampuan memecahkan masalah Fisika kelas eksperimen lebih baik daripada kelas kontrol.
\end{abstract}

Kata kunci: Inkuiri terbimbing, kemampuan pemecahan masalah Fisika, materi Suhu dan kalor, kemampuan awal

\begin{abstract}
The research goal is to exam the influence of the Guided Inquiry strategy on student's problem solving ability of Physics heat and temperature views from prior knowledge of students. This research is a quasi-experimental study with two samples consist of treatment class and control class. The population of research are second semester $X$ grade students of SMAN 10 Malang in the academic year 2015/2016. The samples consist of treatment class and control class that were cluster randon sampling selected. The treatment class learned by using Guided Inquiry, while control class learned by using conventional learning strategy. The learning materials focused on heat and temperature. The data obtained were analyzed by using two way analysis of variance. The effect of learning were analyzed by Tukey's test. The result showed that student's no effect of the initial capabilities of students' problem-solving skills and problem solving ability of Physics on treatment class is better than the control class.
\end{abstract}

Key word : Guided Inquiry, problem solving, heat and temperature, initial ability

\section{PENDAHULUAN}

Tujuan pembelajaran fisika adalah siswa diharapkan dapat menerapkan pengetahuan yang dimilikinya untuk memecahkan masalah pada dunia nyata (Hedge dan Meera, 2012). Sebagai salah satu realitas dari tujuan pembelajaran fisika tersebut diperlukan penguasaan konsep yang baik agar siswa mampu menggunakan pengetahuan yang dimilikinya untuk memecahkan masalah yang lebih kompleks.

Dalam meningkatkan kemampuan pemecahan masalah siswa dituntut untuk meningkatkan pola belajarnya. Dalam 
belajar siswa mengalami kesulitan dalam memahami suatu pengetahuan tertentu, yang salah satu penyebabnya karena pengetahuan baru yang diterima tidak terjadi hubungan dengan pengetahuan sebelumnya (Trianto, 2007).

Pengetahuan awal siswa merupakan salah satu faktor yang dapat berpengaruh terhadap penguasaan konsep siswa. Secara alami dalam suatu kelas, pengetahuan awal siswa bervariasi. Apabila siswa memiliki pengetahuan awal berbeda kemudian diberi pengajaran yang sama, maka pemahaman konsep yang diperoleh akan berbeda-beda sesuai dengan tingkat kemampuannya (Nasution, 2006). Secara tidak langsung, pengetahuan awal dapat mengoptimalkan kejelasan materi-materi pelajaran dan meningkatkan efisiensi penggunaan waktu belajar dan pembelajaran (Trianto, 2007).

Berdasarkan dampak pentingnya kemampuan memecahkan masalah fisika, maka perlu diukur untuk mengetahui tingkat pemahaman siswa. Kemampuan ini umumnya mendapat penekanan dalam proses belajar mengajar. Siswa dituntut untuk memahami atau mengerti sesuatu yang diajarkan, mengetahui sesuatu yang sedang dikomunikasikan dan dapat memanfaatkan isinya.

Akibat dari sulitnya siswa dalam memecahkan permasalahan, sehingga kebanyakan siswa berasumsi bahwa fisika merupakan salah satu mata pelajaran yang dianggap sebagai pelajaran yang sulit, membosankan dan menakutkan oleh siswa. Yang menjadi penyebab pelajaran fisika dianggap sulit adalah permasalahan fisika yang sangat samar (ornec, 2008). Hal ini dikarenakan mata pelajaran fisika sarat dengan rumus-rumus, simbol-simbol dan konsep-konsep yang abstrak, bahkan diluar jangkauan pemikiran siswa. Fisika juga selalu ditampilkan dalam bentuk hitunganhitungan yang rumit dan sulit dipecahkan. Hasil penelitian Soong,dkk (2009) menyatakan bahwa ada beberapa hal yang menyebabkan siswa sulit memecahkan masalah fisika. Beberapa diantaranya tidak memahami pertanyaan, kurangnya kemampuan mengidentifikasi masalah, dan kurangnya pemahaman konsep. Siswa tidak dapat memahami permasalahan dan cara memecahkannya. Hal ini menyebabkan siswa mengalami kesulitan mempelajari fisika sehingga menjadi kendala saat guru membelajarkan fisika.

Kenyataan ini diperkuat dengan melihat hasil rata-rata nilai ujian nasional, bahwa nilai mata pelajaran fisika lebih rendah dari pada mata pelajaran lain, yaitu sebesar 7,1 sedang mata pelajaran lain 7,3 ( badan penelitian dan pengembangan pendidikan, 2013). Demikian pula yang terjadi di SMA Negeri 10 Malang, bahwa nilai mata pelajaran fisika khususnya kelas XI termasuk katagori rendah, yaitu rata-rata hanya 7,0 dibawah nilai mata pelajaran yang lain. Siswa yang memenuhi ketuntasan minimum kurang dari $70 \%$.

Rendahnya nilai fisika ini menunjukkan kemampuan siswa dalam memecahkan permasalahan yang ada di dalam soal masih lemah. Berdasarkan wawancara dengan guru mata pelajaran fisika di SMA Negeri 10 Malang(Ibu Jouni), bahwa kemampuan memecahkan masalah fisika bagi siswa masih rendah, hal ini nampak pada a) siswa kesulitan dalam menafsirkan grafik, simbol \& gambar b) 
menggunakan pendekatan konsep fisika yang tepat dalam menyelesaikan permasalahan, c) menggunakan persamaan matematis dengan tepat, d) mengaplikasikan kondisi fisik dengan permasalahan yang nyata dan e) menyimpulkan hasil ketika diberikan permasalahan.

Salah satu materi fisika yang menyebabkan siswa mengalami kesulitan dalam memecahkan permasalahan fisika adalah materi kalor (Hafizah, 2013). Suhu dan kalor juga merupakan materi yang sering terjadi kesalahan konsep pada siswa dalam pembelajaran yang dilakukan guru (Setyadi, 2012, Beser, 2006) sehingga siswa mengalami kesulitan dalam memecahkan masalah. Dalam pembelajaran materi suhu dan kalor, sebagian guru mengalami kendala bagaimana cara menanamkan konsep secara tepat dalam diri siswa agar siswa mampu mengatasi segala permasalahan fisika dengan tepat. Sehingga sebagian siswa beranggapan bahwa antara suhu dan kalor sama, alat ukur yang digunakan untuk mengukur suhu dan kalor juga dianggap sama (Beser, 2006).

Menurut hasil penelitian alwan (2011) menunjukkan bahwa siswa masih mengalami kesulitan dalam memahami konsep kalor, konsep suhu, perpindahan kalor dan perubahan suhu, titik didih air, titik lebur seng. Siswa masih bingung dengan konsep dan suhu serta belum dapat menjelaskan perbedaan kalor dan suhu. Siswa masih belum bisa memperkirakan suhu ahir campuran dua sampel yang berbeda suhu, namun siswa memahami suhu campuran tidak lebih tinggi sebelum dua sampel dicampur. Siswa menggunakan persamaan $Q$ menentukan jumlah energi kalor dan siswa masih belum mempertimbangkan kalor jenis zat sebagai faktor perubahan suhu.

Berdasarkan karakteristik materi suhu dan kalor diperlukan suatu pembelajaran yang langsung menghadapkan siswa pada kenyataan sehingga konsep yang didapat siswa dapat dilatihkan dalam memahami permasalahan yang dihadapinya. Berdasarkan karakteristik materi suhu dan kalor, dalam memahaminya siswa dituntut untuk melakukan kegiatan praktis sebagai upaya untuk memproses perolehan sementara (gagasan awal) dan melakukan inferensi logis (menyusun simpulan dari informasi ) sampai menemukan hasil pemecahan permasalahan, prinsip fisika meski hanya menurut pandangan siswa. Artinya konsep fisika yang diterima siswa tidak sekedar ingatan semata akan tetapi konsepsi yang disertai alasan yang logis. Karenanya dalam pembelajaran fisika harus ditampilkan secara secara utuh baik proses fisika maupun produk fisika. Guru sebagai pengelola kelas harus bisa memilih strategi pembelajaran yang dapat menampilkan fisika secara utuh, yaitu fisika sebagai proses dan fisika sebagai produk.

Salah satu penyebab gagalnya penerapan strategi pembelajaran fisika di kelas adalah pembelajaran fisika masih cenderung berbasis hafalan teori dan tidak didasarkan pada pengalaman siswa, sehingga pemahaman fisika siswa hanya hafalan. Sadia et al.(2007) mengungkapkan bahwa metode pembelajaran yang dominan digunakan guru di SMP dan SMA pada saat ini adalah metode ceramah $(70 \%)$, metode diskusi (10\%), metode demonstrasi (10\%), dan metode eksperimen (10\%). Selain itu Santyasa, et al. (2012) mengungkapkan 
bahwa model pemberian informasi langsung dari guru ke siswa $(42,59 \%)$, metode ceramah klasik $(16,67 \%)$, dan ceramah tanya jawab $(74,07 \%)$. Dari dua penelitian ini mengisyaratkan bahwa guru lebih banyak berperan sebagai pengendali dan aktif mentransfer pengetahuan sehingga membatasi ruang gerak siswa dalam mengembangkan potensi diri untuk memahami konsep sehingga membuat siswa kesulitan dalam memahami permasalahan yang diberikanoleh guru.

Dalam memecahkan masalah fisika secara mendalam memerlukan suatu perubahan pola berpikir dari menerapkan pembelajaran pembelajaran yang benarbenar cocok dengan karakter pembelajaran fisika. Oleh karena itu, dalam pembelajaran fisika guru hendaknya mampu memilih strategi pembelajaran yang mampu mengaktifkan siswa secara fisik maupun mental, yang mampu meningkatkan pemahaman siswa dalam memecahkan masalah. Strategi pembelajaran yang dapat digunakan dalam pembelajaran fisika adalah strategi pembelajaran inkuiri. Strategi Pembelajaran inkuiri merupakan salah satu strategi pembelajaran yang berlandaskan pada paham konstruktivisme, yang cocok untuk pembelajaran fisika. Pada pembelajaran inkuiri, aktivitas dapat dikembangkan dengan memberi kepercayaan,komunikasi yang bebas, pengarahan diri dan pengawasan yang tidak terlalu ketat dalam pembelajaran (kristyaningsih dkk, 2010). Hal ini seorang guru tidak boleh terlibat terlalu banyak karena tujuan utama pembelajaran adalah untuk membentuk siswa menjadi pebelajar yang mandiri (luginbuhl, 2010;Rapi, 2008).
Hal inilah yang seringkali menjadi kendala karena siswa masih cenderung tergantung dengan guru(rapi, 2008, Sulistina, 2010).

Ada beberapa manfaat bisa diperoleh dari pembelajaran inkuiri. Pertama, siswa akan mempunyai kecakapan memecahkan masalah secara kreatif (widowati, 2008, Setyowati, 2009, Aniesta, 2011, Magfiroh, 2011). Kedua pembelajaran dapat dikembangkan pada pembelajaran lintas ilmu pengetahuan (lee dkk, 2010). Ketiga, pada saat siswa menemukan konsep pada pembelajaran inkuiri akan mengurangi ketegangan dan membuat proses pembelajaran menjdi menyenangkan sehungga respon dan prestasi siswa pada pembelajaran akan jadi lebih baik (luginbuhl, 2010 ; Rapi 2008; Lee dkk, 2010; Wahyudin, 2010). Keempat hasil yang didapatkan adalah siswa sudah bisa mengikuti pembelajaran inkuiri (Luginbuhl, 2010: Kristyaningsih dkk, 2010). Hasil penelitian menunjukkan bahwa pembelajaran inkuiri dapat meningkatkan hasil belajar siswa (Jaya, et al (2014).

Pembelajaran inkuiri dapat diklasifikasikan menjadi beberapa macam. Wenning 2007 membagi inkuiri menjadi 7 macam yaitu: Discovery Learning, Interactive Demonstration, Inquiry Lesson, Guided inquiry labs, Bounded Inquiry Lab, Free inquiry lab dan hypotetical inquiry. Callalan (1992) membagi inkuiri berdasarkan aktivitas siswa menjadi 3 macam. Yaitu, Guided Inquiry, Directed Inquiry dan open inquiry.

Dari penelitian sebelumnya diperoleh informasi bahwa tidak ada perbedaan kualitas proses pembelajaran metode open inquiry dan guided inquiry 
(sadeh, 2009). Meskipun demikian metode open inquiry dan guided inquiry telah memungkinkan terjadinya peningkatan konstruksi pengetahuan dan keterampilan proses serta sikap sains siswa (sulistina, 2009). Penelitian berikutnya, sulistina menemukan bahawa pembelajaran guided inquiry lebih efektif dalam meningkatkan hasil belajar siswa (Kognitif, afektif dan psikomotorik siswa) dibandingkan dengan metode pembelajaran konvensional (sulistina dkk, 2010). Menurut Sadeh dan Zion (2009: 1138), dalam inkuiri terbimbing guru menyediakan masalah dan siswa mengidentifikasi dengan arahan pertanyaan serta menentukan proses dan hasil. Pembelajaran inkuiri terbimbing menekankan pada menanyakan, menelusuri, dan memecahkan masalah (Flick dan Lederman, 2006:17). Pembelajaran inkuiri terbimbing dapat membantu siswa dalam mengembangkan tanggung jawab individu dan kemampuan memahami konsep serta memecahkan masalah (Jack, 2013:11). Proses yang demikian dapat menuntun siswa mengonstruksi konsep karena adanya berbagai pertanyaan untuk mengidentifikasi suatu masalah atau topik sehingga diperoleh suatu pemecahan masalah.

Berdasarkan kajian diatas, dalam dalam meningkatkan kemampuan siswa dalam memecahkan masalah fisika pada materi kalor sangat cocok jika diterapkan dengan strategi pembelajaran inkuiri terbimbing. Dengan mendesain model inkuiri bertujuan untuk mengatasi kekurangan-kekurangan yang terjadi selama proses pembelajaran sebelumnya dan mengetahui pengaruhnya terhadap kemampuan memecahkan masalah siswa.
Oleh karena itu telah dilakukan penelitian dengan judul "Pengaruh model pembelajaran Inkuiri terbimbing terhadap kemampuan memecahkan masalah fisika", agar siswa mampu meningkatkan kemampuannya dalam memecahkan permasalahan yang lebih baik di bidang fisika.

Penelitian ini dilakukan untuk mengetahui kemampuan pemecahan masalah yang lebih tinggi antara siswa yang belajar dengan model pembelajaran inkuiri terbimbing dan konvensional. Adapun hipotesis penelitian ini adalah terdapat perbedaan kemampuan pemecahan masalah fisika siswa yang belajar dengan model pembelajaran Inkuiri terbimbing dan Konvensional, terdapat perbedaan kemampuan pemecahan masalah fisika siswa antara siswa dengan kemampuan awal yang tinggi dan rendah, terdapat interaksi antara strategi pembelajaran dengan kemampuan awal. Kemampuan pemecahan masalah fisika lebih tinggi siswa yang belajar dengan Guided Inquiry daripada yang belajar dengan Konvensional.

Langkah-langkah pembelajaran yang digunakan dalam penelitian ini mengadaptasi dari Tahapan-tahapan yang dikemukakan dalam [sadeh, 2009 dan Trowbidge 1990] sebagai berikut: yang dikemukakan dalam yaitu: tahapan perumusan masalah, tahap pembuatan hipotesis, tahap pengumpulan data., tahap analisis data, tahap pembuatan kesimpulan.

\section{METODE PENELITIAN}

Penelitian ini merupakan penelitian kuasi eksperimen dengan menggunakan dua kelas yaitu satu kelas eksperimen dan satu 
kelas kontrol. Kelas eksperimen adalah kelas yang belajar dengan strategi pembelajaran Inkuiri terbimbing sedangkan kelas kontrol adalah kelas yang belajar dengan Direct Interaction. Pokok bahasan yang diteliti adalah suhu dan kalor. Desain penelitian menggunakan posttest only control group design.

Populasi dalam penelitian ini adalah siswa kelas X SMAN 10 Malang pada semester genap tahun ajaran 2015/2016 yang terdiri atas delapan kelas yaitu kelas dengan jumlah siswa tiap kelas rata-rata berkisar sebanyak 30 siswa. Sampel dipilih secara cluster random sampling dan terpilih kelas $\mathrm{XB}$ dan XF sebagai kelas eksperimen dan kelas XC dan $\mathrm{XH}$ sebagai kelas kontrol. Instrumen perlakuan meliputi Silabus, RPP, dan LKS dibuat dan dilakukan validasi oleh dua orang dosen. Kemampuan pemecahan masalah fisika siswa diukur dengan menggunakan instrumen tes yang berupa soal essai sebanyak 15 soal. Instrumen pengukuran kemampuan pemecahan masalah sebelumnya telah divalidasi isi oleh dua orang dosen dan dilakukan uji coba untuk menentukan validitas dan reabilitasnya. Tes kemampuan pemecahan masalah fisika siswa diperoleh dari hasil postes yang dilakukan setelah pokok bahasan suhu dan kalor selesai.

Analisis data dilakukan dengan menggunakan Analisis Varian dua jalur. Sebelum dilakukan pengujian hipotesis data dilakukan uji prasyarat, yaitu: uji normalitas, uji homogenitas varians, uji homogenitas varians-kovarians, dan uji linearitas. Untuk mengukur kemampuan pemecahan masalah diukur dengan menggunakan rubrik tes kemampuan pemecahan masalah. Adapun proses-proses yang terkandung dalam penilaian kemampuan masalah yang tertera dalam tabel 1.

Tabel 1. Proses-proses kemampuan pemecahan masalah

\begin{tabular}{|c|c|}
\hline Proses & Kegiatan Siswa \\
\hline Useful & Siswa menerjemahkan masa- \\
\hline Description & $\begin{array}{l}\text { lah dan memahami masalah } \\
\text { dengan menggunakan repre- } \\
\text { sentasi yang tepat untuk } \\
\text { merangkum esensi informasi } \\
\text { yang diberikan dalam } \\
\text { masalah, dapat berupa } \\
\text { gambar, grafik, simbol dan } \\
\text { lain-lain }\end{array}$ \\
\hline Physics & Siswa melakukan proses \\
\hline Approach & $\begin{array}{l}\text { pemeliharaan dengan tepat } \\
\text { konsep dan prinsip fisika } \\
\text { yang akan digunakan untuk } \\
\text { memecahkan masalah }\end{array}$ \\
\hline Scientific & Siswa mengaplikasikan dan \\
\hline $\begin{array}{l}\text { Application } \\
\text { of Physics }\end{array}$ & $\begin{array}{l}\text { mengkoneksikan konsep dan } \\
\text { prinsip fisika untuk kondisi } \\
\text { spesifik dalam masalah }\end{array}$ \\
\hline $\begin{array}{l}\text { Mathematical } \\
\text { procedures }\end{array}$ & $\begin{array}{l}\text { Siswa melakukan proses } \\
\text { eksekusi solusi dengan } \\
\text { memilih prosedur dan } \\
\text { mengikuti aturan matematika } \\
\text { dengan tepat }\end{array}$ \\
\hline $\begin{array}{l}\text { Logical } \\
\text { Progression }\end{array}$ & $\begin{array}{l}\text { Siswa melakukan proses } \\
\text { menyampaikan hasil dan } \\
\text { mengevaluasi solusi }\end{array}$ \\
\hline
\end{tabular}

\section{HASIL}

Selama proses pembelajaran berlangsung dilakukan observasi keterlaksanaan proses pembelajaran oleh dua orang observer. Adapun persentase keterlaksanaan pembelajaran dapat dilihat pada Tabel 2 .

Tabel 2. Persentase Keterlaksanaan Pembelajaran

\begin{tabular}{llll}
\hline \multicolumn{2}{c}{ Pertemuan } & \multicolumn{2}{c}{ Kelas } \\
\cline { 3 - 4 } & & E & K \\
\hline $\mathbf{1}$ & G & 83 & 75 \\
& S & 81 & 73 \\
\hline
\end{tabular}




\begin{tabular}{llll}
\hline \multicolumn{2}{c}{ Pertemuan } & \multicolumn{2}{c}{ Kelas } \\
\cline { 3 - 4 } & & E & K \\
\hline $\mathbf{2}$ & $\mathrm{G}$ & 90 & 86 \\
& $\mathrm{~S}$ & 98 & 85 \\
$\mathbf{3}$ & $\mathrm{G}$ & 87 & 91 \\
& $\mathrm{~S}$ & 88 & 89 \\
$\mathbf{4}$ & $\mathrm{G}$ & 93 & 90 \\
& $\mathrm{~S}$ & 92 & 90 \\
$\mathbf{5}$ & $\mathrm{G}$ & 92 & 88 \\
& $\mathrm{~S}$ & 93 & 90 \\
Rata- & $\mathrm{G}$ & 89 & 86 \\
rata & $\mathrm{S}$ & 88 & 85 \\
\hline E & : Eksperimen & \\
K & : Kontrol & \\
G & : Guru & & \\
S & : Siswa
\end{tabular}

Berdasarkan persentase pada Tabel 2 menunjukkan bahwa siswa dan guru pada kelas eksperimen dan kontrol secara keseluruhan semakin memahami proses pembelajaran dari pertemuan ke pertemuan berikutnya. Sehingga dapat dikatakan bahwa kemampuan pemecahan masalah fisika siswa terjadi akibat proses pembelajaran ini.

Data kemampuan pemecahan masalah fisika siswa diperoleh melalui tes pada akhir penelitian. Sebelum dilakukan pengujian hipotesis, kedua data tersebut dilakukan uji prasyarat seperti uji normalitas dan uji homogenitas.

Hasil uji normalitas yang dilakukan dengan uji liliefors mendapatkan untuk penguasaan konsep dan kemampuan pemecahan masalah pada kelas eksperimen dan kontrol data terdistribusi normal. Data bersifat homogen saat diuji sendiri-sendiri. Kedua data juga bersifat linear.

Data kemampuan pemecahan masalah setelah dilakukan uji prasyarat dilanjutkan pengujian hipotesis pertama dengan menggunakan uji two way anova. Hasil pengujian two way anova dapat dilihat pada Tabel 3. Uji Anova dua jalur menunjukkan hasil (sig $0,00<\alpha$ ) ini berarti $\mathrm{H}_{0}$ ditolak dan $\mathrm{H}_{1}$ diterima bahwa terdapat perbedaan kemampuan pemecahan masalah siswa yang belajar dengan Inkuiri terbimbing (kelas eksperimen) dan Direct Interaction (kelas kontrol). Uji anova pada hipotesis ke dua menunjukkan hasil (sig $0,00<\alpha)$ ini berarti $\mathrm{H}_{0}$ ditolak dan $\mathrm{H}_{1}$ diterima bahwa terdapat perbedaan adanya perbedaan antara siswa yang memiliki pengetahuan awal yang tinggi dengan pengetahuan awal yang rendah. Hasil ratarata kemampuan pemecahan masalah dilihat dari kemampuan awal siswa dilihat pada gambar 1.

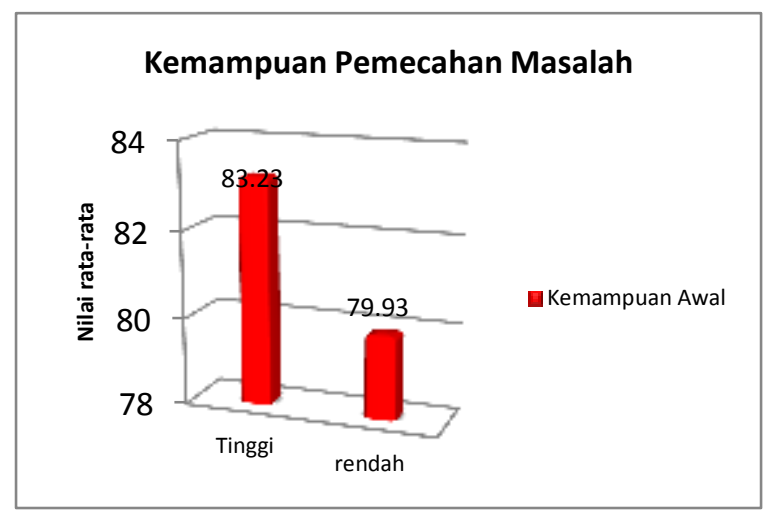

Gambar 1. Diagram rata-rata kemampuan Pemecahan masalah dilihat dari kemampuan awal

Nilai rata-rata r kemampuan
pemecahan masalah kedua kelas
ditunjukkan oleh Diagram pada Gambar 1
yang memberikan arti bahwa kemampuan
awal siswa dapat mempengaruhi
kemampuan pemecahan masalah siswa. Hal
ini sejalan dengan apa yang disampaikan
Nasution (2006) bahwa Apabila siswa


memiliki pengetahuan awal berbeda kemudian diberi pengajaran yang sama, maka pemahaman konsep yang diperoleh akan berbeda-beda sesuai dengan tingkat kemampuannya. Hal ini juga senada dengan apa yang disampaikan triyanto (2007) bahwa pengetahuan awal dapat mengoptimalkan kejelasan materi-materi pelajaran dan meningkatkan efisiensi penggunaan waktu belajar dan pembelajaran.

Uji two way anova pada hipotesis ke tiga menunjukkan hasil (sig $0,00<\alpha)$ ini berarti $\mathrm{H}_{0}$ ditolak dan $\mathrm{H}_{1}$ diterima bahwa ada interaksi antara strategi pembelajaran dengan kemampuan awal.

Hipotesis keempat dilakukan pengujian dengan uji Tukey. Hasil uji Tukey menunjukkan bahwa siswa yang belajar dengan Inkuiri Terbimbing (kelas eksperimen) memiliki kemampuan pemecahan masalah yang lebih tinggi dibandingkan siswa yang belajar dengan Direc Interaction (Kontrol). Hasil rata-rata kemampuan pemecahan masalah pada strategi pembelajaran Inkuiri terbimbing dan Konvensional pada gambar 2.

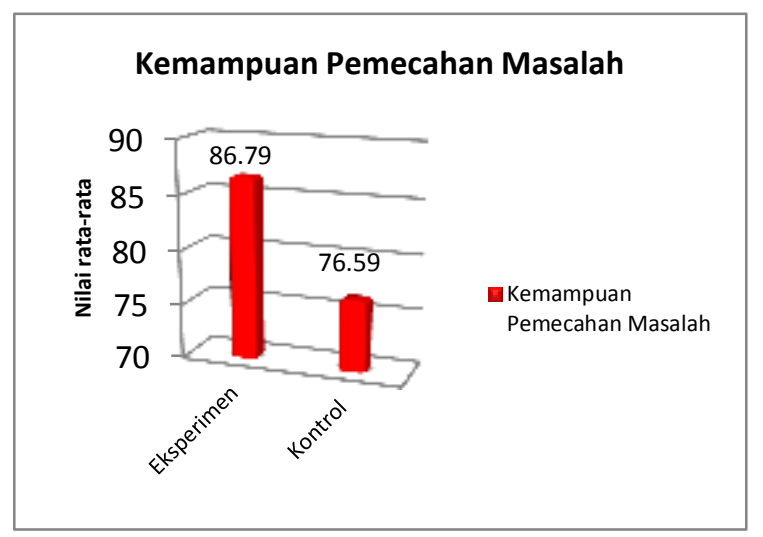

Gambar 2. Diagram rata-rata kemampuan Pemecahan masalah
Nilai rata-rata

kemampuan pemecahan masalah kedua kelas ditunjukkan oleh Diagram pada Gambar 2 yang memberikan arti bahwa model pembelajaran Inkuiri terbimbing dapat meningkatkan kemampuan pemecahan masalah siswa. Hal ini sejalan dengan apa yang disampaikan Jack (2013) Pembelajaran inkuiri terbimbing dapat membantu siswa dalam mengembangkan tanggung jawab individu dan kemampuan memahami konsep serta memecahkan masalah. Flick dan Lederman (2006) juga menyatakan bahwa Pembelajaran inkuiri terbimbing menekankan pada menanyakan, menelusuri, dan memecahkan masalah.

\section{SIMPULAN}

Berdasarkan hasil penelitian dan pembahasan yang telah dilakukan kesimpulan penelitian ini adalah terdapat pengaruh positif yang signifikan dari strategi pembelajaran Inkuiri terbimbing dan kemampuan awal siswa terhadap kemampuan pemecahan masalah fisika siswa. Siswa yang belajar dengan model pembelajaran Guided Inquiry juga mempunyai kemampuan pemecahan masalah yang lebih tinggi daripada siswa yang belajar dengan Direct Interaction .

\section{DAFTAR PUSTAKA}

Alwan, A.A. 2011. Misconception of Heat and Temperature among Physics Students. Procedia Social and Behavioral Sciences, 12.

Baser, Mustofa. Fostering Conceptual Change by Cognitive Conflict Based Instruction on student' Understanding of Heat and Temperature Concepts. Eurasia Journal of Mathematics, 
Science and Technology Education, vol. 2 no. 2, 2006, pp 96-113

Badan Pusat Statistik. (2013, Juli) bps.go.id. [Online].

Callahan, J.E, Clark, L.H. Kellough, R. 1992. The middle and secondary Schools. New York: Maanillan Publishing Company.

Flick L.B \& Lederman N.G Ed, 2006, Scientific Inquiry and the Nature of Science; Implication for learning, and teacher education (pp. 301-317). Dordrecht, The Netherlands; springer

Hafizah, E. 2013. Pengaruh Model Pembelajaran Anchored Instruction terhadap Penguasaan Konsep dan Kemampuan Pemecahan Masalah Fisika Siswa Kelas X. Jurnal Fisika Indonesia (2013) No: 52, Vol XVIII

Hegde, B. \& Meera, B.N. 2012. How Do They Solve It? An Insight into the learner's approach to the mechanism of physics problem solving. Physics Education Research, 8(1), 010109: 1-9.

Jack, G.U. 2013. Concept Mapping and Guided Inquiry as Effective Techniques for teaching Difficult Concepts in Chemistry: Effect on students' academic Achievement. Journal of education and practice, 4 (5): 9-15

Jaya, I.M. , I. W. Sadia, I.B.P.Arnyana. Pengembangan Perangkat Pembelajaran Biologi Bermuatan Pendidikan Karakter Dengan Setting Guided Inquiry Untuk Meningkatkan Karakter Dan Hasil Belajar Siswa SMP. eJournal Progr am Pascasarjana Universitas Pendidikan Ganesha
Program Studi IPA (Volume 4 Tahun 2014)

Kristianingsih, D.D., Sukiswo, S.E. \& Khanafiyah, S. 2010. Peningkatan hasil belajar siswa melalui model pembelajaran inkuiri dengan metode pictorial Ridlle pada pokok bahasan alat-alat optik di SMP. Jurnal Pendidikan fisika Indonesia vol 6No 1 Januari 2010

Lee, H.S, Linn, M.C., Varma, K. \& Liu, O.L. 2010. How Do Tecnology Enhanced Inquiry Science Units Impact Clasroom Learning?. Journal of Research in Science Teaching volume 43 January 2010.

Luginbuhl, L. 2010. Self-monitoring to minimize student resistence to inquiry Journal Physics Teacher Education. Online, 5 (3), Winter 2010.

Nasution, S. 2006. Kurikulum dan Pengajaran. Jakarta : Bumi aksara.

Ornek, F., Robinson, W.R., \& Haugan,M.P.2008. What makes physics difficult?. International Journal of Environmental \& Science Education. 3(1). (Online). (http://eric.ed.gov/?q=physics+educatio $\mathrm{n} \& \mathrm{ft}=$ on\&pg=3\&id=EJ894842).

Diakses 21 Januari 2014.

Sadeh, I. \& Zion, M. 2009. The Development of Dynamic Inquiry Performances within an Open Inquiry Setting: A Comparison to Guided Inquiry Setting. Journal of research in Science Teaching, 46(10): 1137-1160

Selcuk, G. S., Caliskan, S. \& Erol, M. 2008. The effects of Problem Solving Instruction on Physics Achievement, 
Problem Solving Perfomance and strategi Use. Lat. Am. J. Phys. Educ (online), 2 (3)

Setiyowati, T., Sukisno, M. \& Mindyarto, B.N. 2009. Pengajaran Gelombang Elektromagnetik Menggunakan Pendekatan Teori Intelegensi Ganda Untuk Siswa Kelas X SMA. Jurnal Pendidikan Fisika Indonesia 5 (2009) 20-25.

Setyadi, Eko K. Miskonsepsi Tentang Suhu dan Kalor pada Siswa Kelas 1 di SMA Muhammadiyah Purworejo, Jawa Tengah. Berkala Fisika Indonesia, vol. 4, no. 2,2012, pp. : 46-49.

Sulistina. O., Dasna, I.W \& Iskandar, S.M. 2010. Penggunaan Metode Pembelajaran Inkuiri Terbuka dan Inkuiri Terbimbing dalam Meningkatkan Hasil Velajar Kimia Siswa Kelas X SMA Laboratorium Malang. Jurnal Pendidikan Dan Pembelajaran, Volume 17, Nomor 1 April 2010.

Wahyudin. \& Sutikno, A.I. 2010. Keefektifan Pembelajaran Berbantuan Multimedia menggunakan Metode Inkuiri

Wenning, C.J. 2010. Levels of inquiry: Using inquiry spectrum learning sequences to teach science, Journal Physics Teacher Education. Online 5(3). Winter 2010.

Widowati, A. 2008. Peningkatan Kemampuan Divergent Thinking Dengan Menerapkan Pendekatan Modified Free Inquiry Dalam Pembelajaran Sains. Jurnal Penelitian Dan Evaluasi Pendidikan, Nomor 1, Tahun XI, 2008.
Soong, B., Mercer, N \& Shin, S. 2009. Students difficulties when solving phisics problem: Result from an ICTinfused Revision Intervention. Proceding of the $17^{\text {th }}$ international converence in education. 